\title{
Periódicos Científicos em Turismo no Brasil: dos boletins técnico-informativos às revistas científicas eletrônicas ${ }^{1}$
}

\author{
Tourism Scientific Periodicals in Brazil: \\ from technical-informative reports to electronic \\ scientific journals
}

\section{Mirian Rejowski \\ Mariana Aldrigui ${ }^{3}$}

\begin{abstract}
RESUMO: Estudo da comunicação científica em turismo no Brasil, com os seguintes objetivos: traçar um panorama evolutivo dos periódicos técnicocientíficos, a partir de suas propostas editoriais; compreender a função dessas publicações na evolução do conhecimento científico; e discutir a situação atual e as tendências das revistas científicas em turismo no Brasil. $\mathrm{O}$ artigo apresenta uma síntese descritiva dos principais periódicos científicos em turismo publicados no Brasil a partir da década de 1970, caracterizando três fases de evolução - fase inicial intermitente, fase da inovação científica e fase da expansão científica.
\end{abstract}

PALAVRAS-CHAVE: turismo; comunicação científica; periódicos científicos; propostas e tendências editoriais; Brasil.

ABSTRACT: Essay on the tourism scientific communication in Brazil, aiming to overview the evolution of technical-scientific periodicals, considering

1. Esta pesquisa contou com a colaboração de Rafaela Ferreira de Lima, aluna do Bacharelado em Lazer e Turismo da Escola de Artes, Ciências e Humanidades da USP (USP Leste).

2. Bacharel em Turismo, doutora em Ciências da Comunicação e livre-docente em Teoria do Turismo e do Lazer pela Universidade de São Paulo. Docente do Mestrado em Hospitalidade, da Universidade Anhembi-Morumbi. Pesquisadora do CNPq - Conselho Nacional de Pesquisa e Desenvolvimento. Diretora-presidente da ANPTUR - Associação Nacional de Pesquisa e Pós-graduação em Turismo. Contato: mirwski@gmail.com

3. Bacharel em Turismo e mestre em Ciências da Comunicação pela Escola de Comunicaçōes e Artes da USP. Docente do Bacharelado em Lazer e Turismo da ECA-USP. Doutoranda em Geografia na Universidade de São Paulo. Presidente da Associação Brasileira de Bacharéis em Turismo - seccional São Paulo. Contato: aldrigui@usp.br. 
their editorial lines; understand these publications function on the evolution of scientific knowledge; and discuss the actual status and tendencies of the Tourism scientific publications in Brazil. Presents a descriptive synthesis of the main scientific periodicals published in Brazil since 1970, characterizing three evolution phases - initial intermittent phase, scientific innovation phase and scientific expansion phase.

KEYWORDS: tourism; scientific communication; scientific periodicals; editorial purposes and tendencies; Brazil.

\section{Considerações iniciais}

Na comunicação científica em qualquer área ou campo de estudo, destacamse os periódicos de pesquisa ou revistas científicas, cuja característica básica é a sua regularidade e rapidez na disseminação do conhecimento. De acordo com Gonçalves, Ramos \& Castro (2006), sustentam-se no princípio de validação do mérito e do método científico pela comunidade científica, num processo conhecido como peer review (revisão pelos pares), referendando a qualidade individual dos artigos científicos. Assim, asseguram um fluxo contínuo de informações sobre os resultados de pesquisas e possibilitam a dinâmica e evolução do processo de conhecimento em determinada área (Rejowski, 1995: 29).

[...] o papel principal do periódico científico é o de registrar o conhecimento científico e disseminar a informação, e com isso promover a evolução do conhecimento na área de estudo de uma dada especialidade (Bertuzzo, 2004: 11).

Kuhn (apud Côrtes, 2006, p. 47), ao abordar o papel de livros e periódicos na evolução de um paradigma, destacou, inclusive, a função desses últimos, como permitindo:

[...] a discussão de aspectos mais específicos e a resolução de problemas relacionados a um modelo ou paradigma, função que cumprem melhor do que os livros, pois podem ser impressos com maior facilidade e a custos inferiores do que aqueles necessários à publicação de um livro.

Com isso, compreende-se o porquê de as revistas científicas serem "utilizadas como fonte de avaliação da produção científica de pesquisadores e instituiçoes, por meio de indicadores de citação, autoria, co-autoria e acesso" (Gonçalves, Ramos \& Castro, 2006: 165). Estudos sobre ranking de periódicos (Pechlaner et al., 2004; McKercher, Law \& Lam, 2006) e critérios de aprovação de artigos (Yulsel, 2003) são alguns exemplos, como o explicitado a seguir.
- Yuksel (2003) analisou os critérios usados pelos referees de manuscritos submetidos à publicação em periódicos científicos de turismo, viagem e hospitalidade, de âmbito internacional, com base em pesquisa junto a avaliadores dos seguintes periódicos: Annals of Tourism Reseach, Journal of Travel Research, Tourism Management, Journal of Hospitality and Tourism Research, Journal of Travel and Tourism Marketing, e Anatólia - An International Journal of Tourism and Hospitality Research.

- McKercher, Law \& Lam (2006) desenvolveram um estudo global sobre a literatura coletiva (periódicos científicos) junto a acadêmicos de turismo e hospitalidade. Os resultados mostram que essa comunidade científica, coletivamente, avalia as revistas científicas em uma clara hierarquia, baseada na combinação de consciência e na percepção da qualidade dessa literatura.

- Pechlaner et al. (2004) descreveram que os estudos sobre rankings de periódicos consideram tanto dados objetivos (contagem de citação) como a qualidade de percepção de experts. Nesse sentido, apresentam uma avaliação de revistas científicas de turismo e hospitalidade entre a comunidade científica, de acordo com a freqüência de leitores, relevância científica e prática, reputação geral e importância de publicar a carreira acadêmica dos pesquisados.

No entanto, alguns problemas no processo de comunicação científica devem ser mencionados, como os relacionados a seguir.

- O acesso às publicações não é totalmente democratizado ou generalizado, especialmente no caso de publicações impressas, pois o custo de distribuição aumenta conforme a distância geográfica.

- Muitas revistas científicas dependem de subsídios das instituições às quais se vinculam ou de verbas de órgãos financiadores, o que compromete a sua periodicidade, o número de páginas, a distribuição e, até, a própria longevidade.

- A pressão exercida pelas instituições para que seus pesquisadores e/ou docentes publiquem nos veículos por elas editados desencadeia uma explosão informacional, gerando o questionamento da qualidade dos artigos científicos.

- "A diminuição do impacto de novidade exercido pelos artigos, devido à ação dos colégios invisíveis, mais eficientes do que a revista científica na transferência da informação", encurta o "tempo de execução das tarefas de busca e processamento da informação" (Weitzel, 2006: 101). 
Mesmo com esses entraves, nota-se o crescimento da quantidade de revistas científicas eletrônicas, com menores custos de produção e distribuição, indicando as seguintes tendências:

[...] a publicação totalmente eletrônica, explorando cada vez mais recursos hipertextuais e multimídia; o gerenciamento eletrônico do fluxo editorial; a valorização do artigo como unidade informacional; a interoperabilidade entre os sistemas e programas de revistas eletrônicos existentes e o acesso aberto à informação (open access) (Gonçalves, Ramos \& Castro, 2006: 185).

Nas pesquisas realizadas acerca da comunicação científica em turismo, verificou-se a falta de registros sobre a publicação dos periódicos técnico-científicos no Brasil, exceto por alguns estudos particulares sobre as revistas Turismo em Análise e Turismo: Visão \& Ação. Percebeu-se, então, a necessidade de se resgatarem informações sobre as propostas editoriais dessas publicações, a partir da organizaçāo da atividade turística no país, com a criação da EMBRATUR, em 1966, e da criaçāo dos primeiros cursos superiores de Turismo, no início da década de 1970.

A partir desta constatação, definiram-se as seguintes questões de pesquisa:

- como os periódicos científicos em turismo evoluíram editorialmente no Brasil?

- qual o papel e as tendências dessas publicações no fluxo de comunicação científica em turismo?

Este artigo caracteriza-se como uma pesquisa exploratória, que procura analisar inicialmente essa questão, com os objetivos de:

- compreender a evolução dos periódicos científicos (boletins e revistas) editados no Brasil, a partir da criação do primeiro curso superior de Turismo, em 1971;

- analisar suas propostas editoriais, como fundamento para a compreensão da função dessas publicações na evolução do conhecimento científico em turismo;

- identificar tendências da comunicação científica em turismo, no tocante à edição, à distribuição e ao conteúdo.

Entende-se por comunicação científica o processo que engloba desde a produção até a inserção da informação nos canais de comunicação utilizados no meio científico. Tratado como um sistema de comunicação, divide-se em dois domínios, o formal e o informal, os quais se relacionam de maneira interdependente $\mathrm{e}$ complementar (Mueller, 1994; Minozzo \& Rejowski, 2004). O periódico científico se insere no domínio do canal formal como uma fonte de informação escrita, armazenável e necessariamente pré-avaliada. Como uma publicação em qualquer suporte, é editada em unidades físicas sucessivas (fascículos), sob um mesmo título, a intervalos regulares ou irregulares de tempo, com designações numéricas e/ou cronológicas, e com conteúdo especializado em uma determinada área ou campo de conhecimento, destinada a ser continuada indefinidamente (Minozzo \& Rejowski, 2004; ABNT, 2002 - NBR 6.023). E o informal?

O presente texto se inicia por meio de uma síntese descritiva dos principais periódicos científicos de turismo na Europa, nos Estados Unidos e na América do Sul, para, em seguida, tratar com destaque a problemática no Brasil, caracterizando três fases de evolução desse veículo de comunicação científica. Esta pesquisa fundamenta-se nos estudos de Minozzo \& Rejowski (2004) e de Bertuzzo (2004), na consulta a registros de aulas de pós-graduação de Rejowski, a sites da Internet, em fascículos de periódicos de turismo (coletados ao longo dos últimos dez anos ou disponíveis em bibliotecas universitárias/centros de pesquisa ${ }^{4}$ ), e em dados coletados via correspondência eletrônica enviada aos editores dos periódicos.

Periódicos científicos em turismo na Europa e nas Américas: síntese de algumas revistas referendadas

Como o turismo é um campo recente de estudos e pesquisas, as revistas científicas não são abundantes quando comparadas às de áreas com maior tradição científica (geografia, sociologia etc.). Seus conteúdos, na forma de artigos científicos, enfocam diferentes temas, "alinhados a determinadas filosofias e objetivos de cada periódico em particular", sendo que "cada um deles cumpre certas funções de pesquisa e desenvolvimento na área" (Rejowski, 1995: 29). Citam-se, por exemplo, os seguintes periódicos ainda hoje ativos, com base em estudo de Minozzo \& Rejowski (2004: 5-6), e na consulta dos seus respectivos sites:

- Revue du Tourisme, criada em 1946, deu origem à AIEST - Association Internacionale d' Experts Scientifiques du Turisme ${ }^{5}$, sendo o seu órgão oficial. De periodicidade trimestral, "objetiva contribuir para o aprofundamento do turismo como fenômeno interdisciplinar, provendo reflexões

4. Bibliotecas da Universidade de São Paulo e da Universidade Anhembi Morumbi, e acervo do NEAHTUR - Núcleo de Estudos de Administração Hoteleria de Turismo do Centro Universitário Ibero-americano, em São Paulo.

5. A AIEST foi fundada oficialmente em 1951, e sua sede é em Saint Gallen (Suíça). 
para o progresso das questões e dos métodos de pesquisa na área”.

- Journal of Travel Research, criado em 1962, é editado trimestralmente pela TTRA - Travel and Tourism Research Association, nos Estados Unidos. "Oferece informações úteis e novos pontos de vista de pesquisas sobre viagem aos educadores e profissionais de turismo".

- Estudios Turísticos, de periodicidade trimestral, é editada na Espanha, desde 1963, pelo Instituto de Estudios Turísticos, órgão ligado à Secretaria Geral de Turismo. É dirigida a universidades, organismos nacionais e internacionais, profissionais e estudiosos, e sua temática abrange aspectos econômicos, estatísticos, tecnológicos, ecológicos, geográficos e sociológicos relativos ao turismo, a viagens, recreação e lazer.

- Annals of Tourism Research, editado inicialmente em 1973, pela Wisconsin-Sout University, nos Estados Unidos, e, atualmente, em parceria com a Editora Pergamon, tem periodicidade trimestral. "Focaliza perspectivas acadêmicas em turismo e procura motivar a contribuição de várias disciplinas, expandindo as fronteiras do conhecimento nessa área".

- Tourism Management, criado em 1980 com o nome International Journal of Tourism Management, publicado pela University of Surrey, e, atualmente, pela Editora Elsevier (Inglaterra), com periodicidade bimestral. Aborda o turismo em "uma aproximação interdisciplinar, enfocando seus aspectos de planejamento e ética, em âmbito internacional, nacional e regional, assim como estudos específicos de gestão [...]".

- Estudios y Perspectivas em Turismo começou a ser publicado em 1991, com o título Revista Latinoamericana de Turismo, na Argentina, pelo CIET - Centro de Investigaciones y Estudios Turísticos. Promove "a análise do turismo sob a ótica das Ciências Sociais e constitui um fórum interdisciplinar de expansão das fronteiras do conhecimento turístico". 6

- Sustainable Tourism surgiu em 1993, editado pela Sheffield Hallam University, na Nova Zelândia, de periodicidade bimestral. Oferece uma compreensão crítica e aprofundada das relações entre turismo e desenvolvimento sustentável, explorando os aspectos econômicos, sociais, culturais, políticos, organizacionais ou ambientais do tema.

Com exceção da revista Estudios Turísticos, que é ligada ao Ministério da Economia da Espanha, todas as outras se originaram dentro de universidades com

6. Dentre outros periódicos editados na América do Sul, podem ser citados: RUTA - Revista Universitária, editada pela Universidad de la Serena (Chile), desde 1994; Gestión Turistica, pela Universidad Austral de Chile, desde 1995; e Aportes y Transferencias - Tiempo Libre, Turismo y Recreación, pelo Centro de Investigaciones Turísticas da Universidad Nacional del Mar del Plata, desde 1997. centros de pesquisa ou programas na área de turismo; portanto, no meio acadêmico. Verificou-se, também, que revistas tradicionais, como a Annals of Tourism Research e a Tourism Management, vêm sendo impressas por meio de parcerias com editoras privadas de renome, no caso a Pergamon e a Elsevier, respectivamente. A única exceção encontrada é a revista latino-americana Estudios y Perspectivas en Turismo, editada por um centro de pesquisas particular; portanto, sem ligação com alguma universidade.

Nota-se que, nas décadas de 1970 e 1980, os periódicos científicos tratavam do turismo sob uma ótica mais genérica, mas, a partir de meados de 1990, surgiram aqueles especializados em segmentos do turismo. É o caso do Sutainable Tourism (1993), já citado, e de outros, como o Journal of Sport Tourism (1995) e o Journal of Ecotourism (2002). Vale lembrar, ainda, que todas essas publicações têm como editores responsáveis ou membros de seus conselho editorial pesquisadores reconhecidos internacionalmente, referendando o mérito que a comunidade científica em turismo neles deposita.

Comunicação científica em turismo no Brasil: evolução dos periódicos científicos

A fim de compreender a evolução dos periódicos científicos de turismo no Brasil, foram reunidos dados sobre um conjunto de boletins e revistas, os quais foram ordenados a partir da data de sua criação, em três fases distintas. A primeira, denominada fase inicial intermitente, reúne periódicos das décadas de 1970 e 1980; a segunda, fase da inovação científica, refere-se a periódicos criados na década de 1990, e, por fim, fase da expansão científica, que congrega os periódicos da década de 2000 .

\section{Fase inicial intermitente - periódicos técnico-informativos nas} décadas de 1970 e 1980

De 1970 a 1980, identificaram-se cinco periódicos impressos na área de turismo, sendo três boletins e duas revistas de caráter técnico-informativo (Tabela 1). A maioria desses periódicos $(80 \%)$ era editada por instituições de ensino superior com curso de Bacharelado em Turismo no eixo Rio-São Paulo, e pereceram na década seguinte. Apenas os periódicos editados pela Pontifícia Universidade Católica de Campinas e pela EMBRATUR ${ }^{7}$, na época denominada Empresa Brasi-

7. Hoje, a sigla EMBRATUR significa Instituto Brasileiro de Turismo, ligado ao Ministério do Turismo. 
leira de Turismo, foram editados também na década de 1980 (até 1983 e 1988, respectivamente).

No início da década de 1970, surgiram duas revistas técnico-informativas em São Paulo, editadas por faculdades pioneiras no ensino superior de Turismo no Brasil: a Rota 2000, pela Faculdade Ibero-americana de Letras e Ciências Humanas, e a Estudos Turísticos, pelas Faculdades de Turismo do Morumbi e da Guanabara. Como publicações oficiais dessas instituições de ensino superior (IES), ambas pareciam refletir uma certa concorrência entre tais instituições, pois tiveram início em outubro de 1972 (Rota 2000) e em junho de 1973 (Estudos Turísticos), com propostas editoriais similares, conforme mostrado na Tabela 1.

A Estudos Turísticos teve o mesmo nome de tradicional revista científica de turismo editada na Espanha (Estudios Turísticos), e a Rota 2000 projetou-se no futuro (praticamente 30 anos à frente), talvez refletindo o desenvolvimento apregoado por grandes realizações no transporte rodoviário ou o conceito de rota em viagens turísticas. Mantidas pelas IES, que as publicavam como uma forma de propaganda institucional, e por anunciantes, não foi possível obter registros da data de encerramento das edições, pois se teve acesso apenas a fascículos do seu primeiro ano de publicação.

Em 1976, a EMBRATUR lançou o Informativo EMBRATUR, um boletim de caráter técnico-informativo, como um canal de comunicação das suas ações junto ao trade turístico, na gestão de Miguel Colasuonno. Com a evolução de sua equipe de pesquisadores, esse boletim passou a publicar artigos científicos curtos, razão pela qual se pode considerá-lo como um antecedente dos periódicos técnico-científicos na área (Minozzo \& Rejowski, 2004).

É interessante observar que, nos dois últimos anos da década de 1970, surgiram dois boletins ligados a centros de pesquisas turísticas de universidades públicas de tradição religiosa, abaixo indicados:

- 1978 - Boletim CEPETUR, editado pelo Centro de Pesquisas Turísticas da Universidade Católica de Petrópolis, instituição pioneira no ensino superior de Turismo no Rio de Janeiro;

- 1979 - Informativo CEPITUR, editado pelo Centro de Informações e Pesquisas Turísticas da Pontifícia Universidade Católica de Campinas, em São Paulo.

Quanto ao formato, as publicações citadas oscilavam entre o formato A4 $(21,0$ x 29,7 cm) e o ofício $(21,5 \times 31,5 \mathrm{~cm})$, com exceção do Boletim CEPETUR, que apresentava um formato menor $(21,5 \times 23 \mathrm{~cm})$. Os dados sobre a periodicidade de tais publicações não se encontram explícitos, depreendendo-se que as revistas e o Boletim CEPETUR seriam mensais ou bimestrais; o Informativo EMBRATUR, quinzenal; e o Boletim CEPETUR, trimestral. Os exemplares das revistas contavam com 40 páginas cada uma, tendo impressão colorida na capa, anúncios e cadernos centrais, e os dos boletins variavam de 8 a 12 páginas, com impressão em branco e preto (uma cor) ou em duas cores. Dados sobre sua distribuição também não aparecem, sugerindo ter sido a mesma gratuita.

Nenhuma dessas publicações apresentava ISSN - International Standard Serial Number, e seus editores ou responsáveis não foram pesquisadores de realce na área, mesmo porque, na época, a pesquisa em turismo era incipiente no Brasil. É interessante observar, ainda, que todos surgiram na década de 1970, e apenas um deles não pereceu na década seguinte, refletindo, assim, a pouca importância desses veículos enquanto disseminação da informação científica em turismo, ou seja, da própria comunicação científica da área.

Tabela 1. Periódicos técnico-informativos em turismo no Brasil - 1970 a 1980

\begin{tabular}{|c|c|c|c|c|}
\hline $\begin{array}{c}\text { Título do } \\
\text { periódico } \\
\text { e ano de } \\
\text { início }\end{array}$ & $\begin{array}{c}\text { Categoria e } \\
\text { periodicidade }\end{array}$ & $\begin{array}{l}\text { Entidade e } \\
\text { local de } \\
\text { publicação }\end{array}$ & $\begin{array}{l}\text { Editor ou } \\
\text { responsável }\end{array}$ & Conteúdo \\
\hline $\begin{array}{l}\text { Rota } 2000 \\
1972 \text { a (?) }\end{array}$ & $\begin{array}{l}\text { Revista técnico- } \\
\text { informativa } \\
\text { / mensal ou } \\
\text { bimestral }\end{array}$ & $\begin{array}{l}\text { Faculdade Ibero- } \\
\text { americana de } \\
\text { Letras e Ciências } \\
\text { Humanas - São } \\
\text { Paulo (SP) }\end{array}$ & $\begin{array}{l}\text { Manoel Teixeira } \\
\text { de Carvalho Filho } \\
\text { (ano 1, n. 1, } \\
\text { outubro de 1972) }\end{array}$ & $\begin{array}{l}\text { Notas breves sobre } \\
\text { notícias da área, artigos } \\
\text { curtos de opinião, } \\
\text { reportagens e } \\
\text { informações variadas, } \\
\text { e artigos, uma matéria } \\
\text { central em destaque, } \\
\text { notícias da faculdade, } \\
\text { notas sobre livros e } \\
\text { anúncios. }\end{array}$ \\
\hline $\begin{array}{l}\text { Estudos } \\
\text { Turisticos } \\
1973 \text { a (?) }\end{array}$ & $\begin{array}{l}\text { Revista técnico- } \\
\text { informativa } \\
\text { / mensal ou } \\
\text { bimestral }\end{array}$ & $\begin{array}{l}\text { Faculdade de } \\
\text { Turismo do } \\
\text { Morumbi e } \\
\text { Faculdade de } \\
\text { Turismo da } \\
\text { Guanabara - } \\
\text { São Paulo (sp) }\end{array}$ & $\begin{array}{l}\text { Edgar Nalini } \\
\text { (ano 1, n. } 4, \\
\text { junho de 1973) }\end{array}$ & $\begin{array}{l}\text { Editorial, reportagens, } \\
\text { entrevistas, } \\
\text { informações variadas, } \\
\text { artigos, uma matéria } \\
\text { central de destaque, } \\
\text { notícias da faculdade, } \\
\text { cartas à redação e } \\
\text { anúncios. }\end{array}$ \\
\hline
\end{tabular}




\begin{tabular}{|c|c|c|c|c|}
\hline $\begin{array}{c}\text { Título do } \\
\text { periódico } \\
\text { e ano de } \\
\text { início }\end{array}$ & $\begin{array}{c}\text { Categoria e } \\
\text { periodicidade }\end{array}$ & $\begin{array}{l}\text { Entidade e } \\
\text { local de } \\
\text { publicação }\end{array}$ & $\begin{array}{l}\text { Editor ou } \\
\text { responsável }\end{array}$ & Conteúdo \\
\hline $\begin{array}{l}\text { Informativo } \\
\text { EMBRATUR } \\
1976 \text { a } 1988\end{array}$ & $\begin{array}{l}\text { Boletim } \\
\text { técnico- } \\
\text { informativo/ } \\
\text { quinzenal }\end{array}$ & $\begin{array}{l}\text { Coordenadoria } \\
\text { de Comunicação } \\
\text { Social da Empresa } \\
\text { Brasileira de } \\
\text { Turismo } \\
\text { (EMBRATUR) - Rio } \\
\text { de Janeiro (RI) }\end{array}$ & $\begin{array}{l}\text { Carlos Cauby } \\
\text { Silveira (ano vII, } \\
\text { n. } 140,30 \text { de } \\
\text { junho de 1982) }\end{array}$ & $\begin{array}{l}\text { Matérias sobre a atuação } \\
\text { da EmBratur, notícias } \\
\text { do mercado, síntese de } \\
\text { eventos e dados } \\
\text { estatísticos, notas } \\
\text { de empresas e } \\
\text { empreendimentos } \\
\text { classificados, legislação } \\
\text { etc. }\end{array}$ \\
\hline $\begin{array}{l}\text { Boletim } \\
\text { CEPETUR } \\
1978 \text { a } 1985\end{array}$ & $\begin{array}{l}\text { Boletim } \\
\text { técnico- } \\
\text { informativo } \\
\text { / mensal e } \\
\text { bimestral }\end{array}$ & $\begin{array}{l}\text { Centro de } \\
\text { Pesquisas } \\
\text { Turísticas da } \\
\text { Universidade } \\
\text { Católica de } \\
\text { Petrópolis (RI) }\end{array}$ & $\begin{array}{l}\text { Evany Rita Noel } \\
\text { (todo o período) }\end{array}$ & $\begin{array}{l}\text { Notícias sobre atividades } \\
\text { da universidade, artigos } \\
\text { técnicos curtos, } \\
\text { reportagens, síntese de } \\
\text { eventos e notas breves. }\end{array}$ \\
\hline $\begin{array}{l}\text { Informativo } \\
\text { CEPITUR } \\
1979 \text { a } 1983\end{array}$ & $\begin{array}{l}\text { Boletim } \\
\text { técnico- } \\
\text { científico / } \\
\text { trimensal }\end{array}$ & $\begin{array}{l}\text { Centro de } \\
\text { Pesquisas e } \\
\text { Informações } \\
\text { Turísticas da } \\
\text { Pontifícia } \\
\text { Universidade de } \\
\text { Campinas (SP) }\end{array}$ & $\begin{array}{l}\text { Maria Fernanda } \\
\text { Freire Luís (ano II, } \\
\text { n. 3, março/abril/ } \\
\text { maio de 1980) }\end{array}$ & $\begin{array}{l}\text { Editorial, sessão } \\
\text { técnico-científica } \\
\text { (artigos), entrevistas e } \\
\text { notas sobre cursos } \\
\text { ou eventos. }\end{array}$ \\
\hline
\end{tabular}

Fonte: Exemplares diversos dos periódicos pesquisados.

Tais publicações disseminavam os resultados de atividades e pesquisas desenvolvidas nesses centros por docentes e discentes de cursos de Turismo, constituindo-se nos primeiros periódicos de que se tem notícia na área. Pelos fascículos consultados, verificou-se que o Informativo CEPITUR apresentava um caráter técnico-científico mais elaborado do que o Boletim CEPETUR, pois publicava um artigo científico formatado como tal, além do editorial e de notas breves. Mas é interessante observar os objetivos que constam do primeiro número deste último:

1. [propiciar] intercâmbio cultural entre as faculdades de Turismo, fazendo com que haja maior relacionamento entre os alunos e a diretoria das mesmas;
2. versar sobre os diversos setores componentes do turismo, ampliando, desta forma, a visão dos interessados nesta área;

3. levar ao conhecimento do leitor, fatos do cotidiano das cidades, que estejam intimamente ligados ao turismo, assim como fazê-lo conhecedor da expressão de cada faculdade.

O encerramento da edição dessas duas publicações, na década de 1980, e a sua não-continuidade ou evolução para uma revista científica refletem a pouca sustentação desses centros enquanto produtores de pesquisas científicas. No caso do CEPETUR, ele foi extinto em 1985'; o CEPITUR permanece como Centro de Pesquisas e Informações Turísticas, no curso de Turismo da PUC de Campinas. A importância desses periódicos pode ser melhor avaliada conforme o depoimento de Evany Noel, ex-editora do Boletim CEPETUR:

Pude perceber a importância do Boletim CEPETUR para a disseminação do conhecimento, pois se tornou uma referência para os professores e alunos. Funcionou, ainda, como um órgão que promoveu a integração e o relacionamento entre professores e alunos de vários estados do País. Ao mesmo tempo, deu visibilidade ao trabalho do Centro de Pesquisas Turísticas, que, mesmo depois de o Curso de Turismo ter fechado', ainda realizou cursos de aperfeiçoamento ministrados por professores do Centro de Capacitação Turística da Organização dos Estados Americanos - OEA/México, que haviam sido meus professores no Curso de Planejamento do Desenvolvimento Turístico. Estes cursos contaram com participantes de todo o Brasil. Logo depois, a UCP realizou, com apoio técnico de especialista do CICATUR - OEA, a primeira Pesquisa da Demanda Turística de Petrópolis.

\section{Fase da inovação científica - surgimento e consolidação de} periódicos científicos na década de 1990

Foram identificados quatro periódicos impressos, todos na categoria de revistas científicas impressas, editados por instituições de ensino superior da Bahia, de Santa Catarina e de São Paulo (Tabela 2). No início da década de 1990,

8. Atualmente, a sigla CEPETUR é utilizada pelo Centro de Pesquisas e Estudos de Turismo da UniverCidade, no Rio de Janeiro.

9. O curso de Turismo da UCP foi paralisado em 1982, por decisão da Universidade, que alegou a queda da procura. 
surgiu a revista Turismo em Análise, uma iniciativa pioneira do curso de Turismo da Universidade de São Paulo, o primeiro periódico científico da área do turismo no Brasil. Em 1992, surgiu o Boletim de Turismo e Administração Hoteleira, editado pelo UNIBERO - Centro Universitário Ibero-americano, de caráter técnico-científico. Apenas seis anos depois, em 1998, surgiram duas outras revistas científicas - Turismo: Visão \& Ação, ligada ao Mestrado em Turismo e Hospitalidade da UNIVALI (Universidade do Vale do Itajaí), e Turismo: Tendências \& Debates, uma iniciativa do Centro de Estudos de Pós-graduação Olga Mettig, da Faculdade de Turismo da Bahia.

Tabela 2. Primeiros periódicos científicos em Turismo no Brasil - 1990

\begin{tabular}{|c|c|c|c|c|}
\hline $\begin{array}{l}\text { Título do } \\
\text { periódico }\end{array}$ & $\begin{array}{c}\text { Categoria e } \\
\text { periodicidade }\end{array}$ & $\begin{array}{l}\text { Entidade e } \\
\text { local de } \\
\text { publicação }\end{array}$ & $\begin{array}{l}\text { Editor ou } \\
\text { responsável }\end{array}$ & $\begin{array}{c}\text { Proposta e } \\
\text { conteúdo } \\
\text { Circulação e } \\
\text { avaliação }\end{array}$ \\
\hline $\begin{array}{l}\text { Turismo em } \\
\text { Análise } 1990\end{array}$ & $\begin{array}{l}\text { Revista científi- } \\
\text { ca semestral }\end{array}$ & $\begin{array}{l}\text { Escola de } \\
\text { Comunicaçōes } \\
\text { e Artes da } \\
\text { Universidade } \\
\text { de São Paulo } \\
\text { - São Paulo } \\
\text { (sp) }\end{array}$ & $\begin{array}{l}\text { Mirian Rejowski } \\
\text { (1990 a 2002); Mi- } \\
\text { rian Rejowski e } \\
\text { Mário Jorge Pires } \\
\text { (2003 a 2006); } \\
\text { Débora Cordeiro } \\
\text { Braga e Mário } \\
\text { Jorge Pires (a } \\
\text { partir de 2007) }\end{array}$ & $\begin{array}{l}\text { Fórum de discussão e pon- } \\
\text { te de comunicação entre a } \\
\text { universidade e a iniciativa } \\
\text { pública e privada, a fim } \\
\text { de preencher a lacuna } \\
\text { existente na literatura } \\
\text { especializada em turismo } \\
\text { no Brasil. Editorial, artigos } \\
\text { científicos, resenhas de } \\
\text { livros e síntese de eventos. }\end{array}$ \\
\hline $\begin{array}{l}\text { Boletim do Cur- } \\
\text { so de Turismo } \\
\text { - } 1992 \text { a } 1994 \\
\text { Boletim dos Cur- } \\
\text { sos de Turismo } \\
\text { e de Adminis- } \\
\text { tração Hoteleira } \\
\text { - } 1995 \text { a } 1997 \\
\text { Boletim de } \\
\text { Turismo e } \\
\text { Administração } \\
\text { Hoteleira - } 1998 \\
\text { a } 2002\end{array}$ & $\begin{array}{l}\text { Revista científi- } \\
\text { ca semestral }\end{array}$ & $\begin{array}{l}\text { Centro } \\
\text { Universitário } \\
\text { Ibero-ameri- } \\
\text { cano (sp) }\end{array}$ & $\begin{array}{l}\text { CETUR } \text { - Claudia } \\
\text { C. de A. Moraes } \\
\text { - 1992 a 1994 } \\
\text { CETUR - 1994 a } \\
1995 \\
\text { Ronaldo Boern- } \\
\text { gen - } 1995 \text { a } \\
1999 \\
\text { Davis Gruber } \\
\text { Sansolo - 2000 } \\
\text { a } 2001 \\
\text { NEAHTUR - Márcia } \\
\text { Midori Matsuura } \\
\text { - } 2002\end{array}$ & $\begin{array}{l}\text { Divulgar as idéias e pes- } \\
\text { quisas realizadas na insti- } \\
\text { tuição. Artigos e trabalhos } \\
\text { acadêmicos pertinentes } \\
\text { às áreas de Turismo e } \\
\text { Hotelaria, produzidos por } \\
\text { docentes, estudantes e } \\
\text { profissionais dessas áreas. }\end{array}$ \\
\hline
\end{tabular}

\begin{tabular}{|c|c|c|c|c|}
\hline $\begin{array}{l}\text { Título do } \\
\text { periódico }\end{array}$ & $\begin{array}{c}\text { Categoria e } \\
\text { periodicidade }\end{array}$ & $\begin{array}{l}\text { Entidade e } \\
\text { local de } \\
\text { publicação }\end{array}$ & $\begin{array}{l}\text { Editor ou } \\
\text { responsável }\end{array}$ & $\begin{array}{c}\text { Proposta e } \\
\text { conteúdo } \\
\text { Circulação e } \\
\text { avaliação }\end{array}$ \\
\hline $\begin{array}{l}\text { Turismo: Visão } \\
\& \text { Ação } 1998\end{array}$ & $\begin{array}{l}\text { Revista cientí- } \\
\text { fica semestral/ } \\
\text { quadrimestral }\end{array}$ & $\begin{array}{l}\text { Universidade } \\
\text { do Vale do } \\
\text { Itajaí (UNIVAul) } \\
\text { - Mestrado } \\
\text { acadêmico } \\
\text { em Turismo } \\
\text { e Hotelaria } \\
\text { - Balneário } \\
\text { Camburiú (sc) }\end{array}$ & $\begin{array}{l}\text { Dóris van de Me- } \\
\text { ene Ruschmann } \\
\text { (1998-2002); } \\
\text { Yolanda Flores e } \\
\text { Silva (2002-2006); } \\
\text { Anete Alberton e } \\
\text { Paulo dos Santos } \\
\text { Pires (2006); } \\
\text { Anete Alberton e } \\
\text { Dóris van de Me- } \\
\text { ene Ruschmann } \\
\text { (2007) }\end{array}$ & $\begin{array}{l}\text { Visão interdisciplinar } \\
\text { do turismo, abordando } \\
\text { temas relevantes, com } \\
\text { perspectivas } \\
\text { provocativas e inovadoras } \\
\text { que refletissem o estado } \\
\text { da arte da produção do } \\
\text { conhecimento na área. }\end{array}$ \\
\hline $\begin{array}{l}\text { Turismo: } \\
\text { Tendências \& } \\
\text { Debates } 1998\end{array}$ & $\begin{array}{l}\text { Revista cien- } \\
\text { tífica anual / } \\
\text { semestral }\end{array}$ & $\begin{array}{l}\text { Faculdade } \\
\text { de Turismo } \\
\text { da Bahia e } \\
\text { SEBRAE-BA } \\
\text { Salvador (BA) }\end{array}$ & $\begin{array}{l}\text { Maria Menezes } \\
\text { do Amaral }\end{array}$ & $\begin{array}{l}\text { Veículo capaz de repensar } \\
\text { a qualificação da mão- } \\
\text { de-obra e dos produtos } \\
\text { para o turismo, com textos } \\
\text { polêmicos, pesquisas } \\
\text { de alunos e professores, } \\
\text { idéias inéditas e trabalhos } \\
\text { produzidos por convida- } \\
\text { dos especiais no Brasil e } \\
\text { no exterior. Apresentação, } \\
\text { editorial e artigos. }\end{array}$ \\
\hline
\end{tabular}

(a) CETUR - Centro de Estudos e Pesquisas em Turismo da Faculdade Ibero-americana de Letras e Ciências Humanas. (b) NEAHTUR - Núcleo de Estudos de Administraçāo Hoteleira e Turismo do Centro Universitário Ibero-americano.

Fonte: Exemplares diversos dos periódicos pesquisados.

A primeira - Turismo em Análise - foi criada em 1990, por um grupo de docentes do curso de Turismo da Escola de Comunicações e Artes da USP, e lançada por ocasião do II Seminário Latino-americano da AMFORT ${ }^{10}$, em São Paulo. Consolidou-se nos anos 1990 como a principal revista científica editada no Brasil, e partiu para um processo editorial profissional em 2003, medianteparceria com a

10. AMFORT - Associação Mundial para a Formação Profissional em Turismo, fundada em Nice, em 1969. Foi substituída pela AMFORTH - Associação Mundial para a Formação Profissional Turística e Hoteleira, também em Nice, em 1998. 
Editora Aleph. Atualmente, publica artigos em português e/ou espanhol, de autores brasileiros e latino-americanos, com uma circulação principalmente nacional.

Foi classificada como revista nacional A na Lista Qualis ${ }^{11}$ da CAPES - Coordenadoria de Avaliação do Ensino Superior, mas o número atual de assinantes vem comprometendo sua existência enquanto veículo de comunicação científica impressa, conforme depoimento de sua atual editora, Debora Cordeiro Braga, além de outros fatores, tais como:

- decréscimo da quantidade de cursos superiores de Turismo, a partir do início do século XXI, e das exigências mínimas do MEC - Ministério da Educação, de literatura especializada nas bibliotecas dos mesmos;

- desativação da linha de pesquisa Turismo e Lazer junto ao mestrado e doutorado em Ciências da Comunicação da USP, e proposta ainda em tramitação interna de um novo Programa de Pós-graduação stricto sensu em Turismo;

- proliferação das revistas eletrônicas na área de turismo e áreas afins no Brasil, a maioria de acesso aberto, possibilitando rapidez na comunicação científica;

- pouco apoio da instituição na qual se encontra, tendo em vista questōes financeiras, tecnológicas (equipamentos) e de recursos humanos, em atividades referentes à responsabilidade do conteúdo da revista.

A segunda - Boletim do Curso de Turismo - manteve-se por dez anos, de 1992 a 2002, e apresentou três propostas editoriais com alteração de nome do periódico e de editores responsáveis (Tabela 2), refletindo a trajetória de seus cursos de Graduação em Turismo e Administração Hoteleira, e de seu mestrado em Turismo, o qual não foi recomendado pela CAPES e deixou de existir em 2002, ocasião em que também se encerrou a publicação do boletim e em que significativas mudanças administrativas aconteceram na IES. Segundo Marcia Midori Matsuura, última editora do periódico, este deixou de ser publicado pela mudança de planejamento estratégico da UNIBERO.

A terceira - Turismo: Visão \& Ação - foi uma iniciativa do Programa de Mestrado em Turismo e Hotelaria da UNIVALI (SC), inicialmente publicada em edição

11. A Lista Qualis classifica um conjunto de periódicos e de eventos científicos (anais), nos quais os docentes e discentes dos programas de pós-graduação stricto sensu publicam os resultados de suas pesquisas e/ou estudos. Esse processo foi concebido pela CAPES para apoiar o seu sistema de avaliação. Os veículos citados pelos programas de pós-graduação são enquadrados em categorias indicativas da qualidade - A, B ou C-, que se conjugam com categorias de circulação - local, nacional ou internacional. bilíngüe (português/inglês). Mas, em face de problemas editoriais, passou a publicar os artigos apenas em português ou inglês, com resumos nessas duas línguas. Sua periodicidade, inicialmente semestral, passou a ser quadrimestral e foi-se aprimorando segundo os critérios avaliativos da CAPES. Obteve a classificação na Lista Qualis como nacional c, no período de 2004 a 2006, e nacional B, a partir de 2007. Paulatinamente, vem se consolidandojunto à comunidade científica em turismo, e se aprimorando sob o ponto de vista editorial, em especial em relação ao seu conteúdo. Segundo seus responsáveis, deverá, nos próximos anos, efetivamente, estender seu alcance de nacional para internacional, e lançar uma edição eletrônica ao lado da impressa (pequena tiragem), a fim de ampliar o alcance de sua circulação.

A quarta - Turismo: Tendências \& Debates - traduz o empenho na consolidação e expansão dos estudos de pós-graduação em Turismo, da Faculdade de Turismo da Bahia (FACTUR), inclusive para um programa de mestrado na área, cujo projeto, no final dos anos 1990, não foi aprovado pela CAPES. Apesar de contar com o apoio do SEBRAE-BA para a sua edição, ela vem apresentando irregularidades em sua periodicidade: um fascículo nos anos de 1998 a 2000, 2002 e 2005, e sua não-publicação nos anos de 2001, 2003, 2004 e 2006. Essa falta de continuidade e os atrasos na publicação de fascículos, embora com conteúdo alinhado à sua proposta editorial, prejudicam a consolidação da revista enquanto veículo de comunicação científica na área. Paulo de Sérgio Mettig, diretor da FACTUR, justificou assim a descontinuidade desse periódico e sua proposta esse ano:

Em 2004, a FACTUR concentrou seus esforços na qualificação dos seus docentes para mestrado e doutorado e suas respectivas publicaçōes. Sendo assim, não foi possível viabilizar a sexta edição da revista, que foi publicada, em 2005, trazendo as primeiras discussōes sobre hospitalidade no Brasil e no mundo. Neste momento, a revista Turismo: Tendências \& Debates passa por uma reestruturação para que seja disponibilizada eletronicamente no site das FAMETTIG. Os artigos já estão sendo finalizados pelos colaboradores e, até o final do ano, inauguraremos mais uma etapa na história de nossas publicaçōes, levando as discussōes contemporâneas sobre o turismo mundial para cada vez mais pessoas.

Dos periódicos científicos desta fase, somente dois deles permanecem ativos - a Turismo em Análise e a Turismo: Visão \& Ação. Ambas têm publicado, em suas ediçōes, artigos de autoria de pesquisadores nacionais e do exterior, e contam com estudiosos de renome do Brasil e do exterior em seu conselho editorial, e com docentes/pesquisadores reconhecidos como editores responsáveis. Tais aspectos referendam a qualidade dessas publicaçōes, enquanto veículos de comunicação científica em turismo. 
Apesar de o periódico editado pela UNIBERO se intitular boletim, ele tem características de revista científica, assim como o editado pela FACTUR. Acredita-se que a trajetória interrompida do Boletim de Turismo e Administração Hoteleira e a falta de continuidade da revista Turismo: Tendências \& Debates sejam resultados de situações particulares nas IES que os editam, ao lado de problemas administrativos e/ou editoriais para a sua realização.

Com exceção do Boletim de Turismo e Administração Hoteleira, as demais revistas desta fase apresentaram uma pequena inserção latino-americana e/ou internacional, embora citassem ter circulação nacional e internacional. Depreende-se que nenhuma delas ainda se posicionou como tal, pois foram ou são classificadas como nacional na Lista Qualis da CAPES, e não constaram em indexadores internacionais, como nas bases de dados do ISI - Institute for Scientific Information ${ }^{12}$.

Quanto ao formato, duas apresentavam o tamanho A4 e duas, o formato de livro ( 15 a $16 \times 21$ a $23 \mathrm{~cm}$ ), sendo a capa colorida (duas a quatro cores) e o miolo em preto e branco (uma cor). Todas priorizavam os artigos científicos na maior parte do seu conteúdo, complementados por resenhas de livros, sínteses de eventos e resumos de dissertações e teses; apresentavam ISSN e normas para publicação de artigos, com padrões similares para recebimento e formatação de trabalhos com base nas normas da ABNT - Associação Brasileira de Normas Técnicas. As revistas atualmente ativas aprimoraram o sistema peer review de avaliação de artigos científicos, constituindo um corpo de consultores ad hoc dentro de diversas temáticas do turismo.

Importa também mencionar que a revista Turismo em Análise já foi objeto de estudos acadêmicos em nível de graduação (Minozzo, 2003) e pós-graduação (Bertuzzo, 2004; Eidt, 2004). Em 2007, esta publicação e a Turismo: Visão \& Ação foram também objeto de interessante estudo sobre a pesquisa em turismo no Brasil, que analisou a distribuição de freqüências e medidas de estatística descritiva dos dados de 373 artigos publicados no período de 1990 a 2005 (Alberton $\&$ Lopes, 2007). Tais dados indicam que essas duas revistas concentram grande parte da produção científica nacional, e têm papel fundamental na disseminação do conhecimento científico em turismo no Brasil.

12. O ISI oferece serviços de bases de dados bibliográficos, "uma cobertura abrangente da mais importante e influente pesquisa realizada em todo o mundo" (Testa, 1998). Seus "dados de citaçōes categorizados por periódicos e publicados em forma de indicadores no Journal Citation Reports (JCR) [...] passaram a ser usados como parâmetro de avaliação de pesquisadores e instituiçōes", como o fator de impacto (Strehl, 2005).
Fase da expansão científica - revistas impressas x revistas eletrônicas na década de 2000

De 2000 a 2007, foram identificados 16 periódicos, alguns de caráter técnicocientífico, pois não publicavam artigos originais de pesquisa nem contavam com a avaliação de artigos no sistema peer review. A maioria priorizava - ou prioriza - a mídia eletrônica (11), sendo que apenas quatro revistas criadas nessa década foram ou são impressas e uma apresentava um formato intermediário - CD-ROM (Tabela 3).

Do total de revistas desta fase, 33\% (cinco) encontram-se desativadas, conforme informações das instituições responsáveis ou mediante consulta a seus respectivos sites: Revista Turismo \& Desenvolvimento, Revista Eletrônica de Turismo, Seminário da Pesquisa em Turismo do Mercosul, Revista UNIBERO de Turismo e Hotelaria, Revista Eletrônica Turismo \& Hospitalidade e Revista Turismo: Dimensões e Perspectivas. A Revista Turismo \& Desenvolvimento, segundo a editora Odaléia T. M. Machado Queiroz, terá continuidade de publicação ainda em 2007.

Das 11 revistas ativas, apenas a Revista Hospitalidade é impressa, indicando a clara tendência de publicações na mídia eletrônica. A maioria publica artigos e resenhas de livros, e, eventualmente, sínteses de eventos, depoimentos ou entrevistas com experts da área. Já o Observatório de Inovação em Turismo publica entrevistas ou depoimentos. Exceto a Revista Eletrônica Turismo \& Hospitalidade (desativada), publicada por iniciativa de um grupo de pesquisadores, todas as demais eram ou são publicadas por instituições de ensino superior. Observa-se, no caso da Revista Eletrônica de Turismo, a não-oferta de cursos na área de turismo. A Revista de Turismo, editada pelas Faculdades Nobel, talvez tenha sido uma evolução da publicação Turismo: Dimensões e Perspectivas, para o meio eletrônico, pois há artigos com data de 2002. No entanto, não se obtiveram maiores informações, e percebe-se a falta de padronização em termos editoriais e de avaliação, ao lado de alguns artigos de opinião - daí a categoria de técnico-científica.

É interessante observar, ainda, a iniciativa da Universidade de Caxias do Sul em editar uma revista em formato de CD-ROM - portanto, um meio intermediário entre o impresso e eletrônico. Todavia, percebeu-se, ao longo dos seus três anos de edição, que sua distribuição e circulação poderia ser maior e mais efetiva se passasse a ser um veículo eletrônico. Entretanto, apesar de essa proposta ter sido decidida no final de 2006, a revista não foi revitalizada.

Com relação ao formato eletrônico, as propostas são variadas, e a Revista Hospitalidade tem o tamanho-padrão de livro. Já o ISSN não figura em um pequeno número delas, além da falta de informações, como início da edição e periodicidade proposta, indicando também fragilidades de padronização editorial, como o caso da Revista de Turismo. 
Apesar da facilidade e da rapidez na disseminação científica em turismo que a revista eletrônica propicia, as revistas criadas nesta fase não apresentam condições para uma efetiva circulação internacional, pois nenhuma é bilíngüe; apenas publicam resumos e palavras-chave em português, inglês e/ou espanhol. Duas dessas revistas - a Revista Brasileira de Pesquisa em Turismo e o Caderno Virtual de Turismo - seguem a recomendação da CAPES e já estão utilizando o software SEER (Sistema Eletrônico de Editoração de Revistas), disponibilizado gratuitamente pelo IBICT - Instituto Brasileiro de Ciência e Tecnologia.

Há, também, uma proposta de outra revista eletrônica, a Revista Eletrônica Cultura \& Turismo, de periodicidade semestral, a ser publicada pela Universidade Estadual de Santa Cruz - Mestrado em Cultura e Turismo - Ilhéus (BA), com a proposta de uma visão multidisciplinar, buscando estimular a troca de informações, a reflexão e o debate sobre a cultura e o turismo com visão crítica, transformadora e promotora de desenvolvimento social. Portanto, percebe-se uma nítida tendência na publicação de periódicos eletrônicos em turismo, acompanhando o que está ocorrendo em outras áreas do conhecimento, inclusive com o estímulo de órgãos cOMO a CAPES e o CNPq.

Mas, ao mesmo tempo em que as revistas eletrônicas agilizam todo o processo editorial, pode-se questionar tanto o seu conteúdo quanto os critérios de usuabilidade, visibilidade e qualidade. Nesse sentido, importa citar alguns resultados do trabalho de Bandeira (2007: 15), sobre cinco periódicos em turismo on-line editados no Brasil: Caderno Virtual de Turismo, RETUR - Revista Eletrônica de Turismo, Patrimônio: Lazer e Turismo, Observatório de Inovação em Turismo e Revista de Turismo.

Quanto à visibilidade, as categorias de indexação e controle de visitas acabam comprometendo a categoria de fator de impacto. [...] com relação à visibilidade,

a revisão por pares, ou melhor, a ausência de revisão por pares é um aspecto identificado e prejudicial ao periódico.

Quanto à qualidade, a falta de um sistema de busca por autores ou textos também pontua contra a publicação, assim como não ter uma pessoa responsável, ou ainda, $[. .$.$] a não-atualização conforme a periodicidade.$

[Em relação à] usuabilidade, [...] num segundo estudo, seriam sugeridas alterações estruturais que poderiam qualificar o espaço virtual disponibilizado na rede.
Tabela 3. Revistas científicas impressas $\mathrm{x}$ revistas científicas eletrônicas em turismo no Brasil - 2000-2007

\begin{tabular}{|c|c|c|c|c|}
\hline $\begin{array}{l}\text { Título do } \\
\text { periódico }\end{array}$ & $\begin{array}{l}\text { Categoria tipo } \\
\text { periodicidade }\end{array}$ & $\begin{array}{l}\text { Entidade e local } \\
\text { de publicação }\end{array}$ & $\begin{array}{l}\text { Editor ou } \\
\text { responsável }\end{array}$ & $\begin{array}{l}\text { Proposta, conteúdo, } \\
\text { circulação e avaliação }\end{array}$ \\
\hline $\begin{array}{l}\text { Revista } \\
\text { Turismo \& } \\
\text { Desenvolvi- } \\
\text { mento } \\
2001 \text { a } 2005\end{array}$ & $\begin{array}{l}\text { Revista científica } \\
\text { impressa } \\
\text { semestral }\end{array}$ & $\begin{array}{l}\text { Centro de Pós-Gra- } \\
\text { duação e Extensão } \\
\text { das Faculdades } \\
\text { da Organização } \\
\text { Paulista Educa- } \\
\text { cional e Cultural e } \\
\text { da Editora Átomo } \\
\text { - Campinas (SP) }\end{array}$ & $\begin{array}{l}\text { Odaléia Telles } \\
\text { Marcondes } \\
\text { Machado } \\
\text { Queiroz }\end{array}$ & $\begin{array}{l}\text { Espaço para a divulgação } \\
\text { da produção científica na } \\
\text { área de turismo, na visão } \\
\text { de que o conhecimento } \\
\text { deve ser construí- } \\
\text { do e compartilhado } \\
\text { coletivamente. Artigos e } \\
\text { comunicações. }\end{array}$ \\
\hline $\begin{array}{l}\text { Caderno } \\
\text { Virtual de } \\
\text { Turismo } \\
2001\end{array}$ & $\begin{array}{l}\text { Revista cienti- } \\
\text { fica eletrônica } \\
\text { quadrimestral }\end{array}$ & $\begin{array}{l}\text { Laboratório de } \\
\text { Tecnologia e } \\
\text { Desenvolvimento } \\
\text { Social - Instituto } \\
\text { Virtual de Turismo } \\
\text { (IVT) - Universidade } \\
\text { Federal do Rio de } \\
\text { Janeiro (RI) }\end{array}$ & $\begin{array}{l}\text { Roberto } \\
\text { Bartholo }\end{array}$ & $\begin{array}{l}\text { Instrumento para } \\
\text { estimular a reflexão e a } \\
\text { discussão sobre o turis- } \\
\text { mo como promotor de } \\
\text { desenvolvimento social, } \\
\text { numa visão multidiscipli- } \\
\text { nar para chegar às suas } \\
\text { imbricações nas variadas } \\
\text { dimensões da sustentabi- } \\
\text { lidade. Artigos e resenhas } \\
\text { de livros. }\end{array}$ \\
\hline $\begin{array}{l}\text { RETUR - Revis- } \\
\text { ta Eletrônica } \\
\text { de Turismo } \\
2002 \text { a ... } \\
\text { (desativada) }\end{array}$ & $\begin{array}{l}\text { Revista científica } \\
\text { eletrônica } \\
\text { semestral }\end{array}$ & $\begin{array}{l}\text { Núcleo de Estudos } \\
\text { Pedagógicos e } \\
\text { Administrativos } \\
\text { (NEPA) - Facul- } \\
\text { dade Cenecista } \\
\text { Presidente Kennedy } \\
\text { - Campo Largo (PR) }\end{array}$ & $\begin{array}{l}\text { Lizete Shizue } \\
\text { Bomura } \\
\text { Maciel e } \\
\text { Alexandre } \\
\text { Shigunov } \\
\text { Neto }\end{array}$ & $\begin{array}{l}\text { Divulgação do conhe- } \\
\text { cimento produzido no } \\
\text { meio acadêmico e cien- } \\
\text { tífico, como resultado de } \\
\text { estudos e pesquisas, arti- } \\
\text { culando ensino, pesquisa } \\
\text { e extensão. Artigos. }\end{array}$ \\
\hline $\begin{array}{l}\text { Seminário da } \\
\text { Pesquisa em } \\
\text { Turismo do } \\
\text { MERCOSUL } \\
2004 \text { a } 2006\end{array}$ & $\begin{array}{l}\text { Revista científica } \\
\text { em CD-Rom } \\
\text { anual }\end{array}$ & $\begin{array}{l}\text { Mestrado em Turis- } \\
\text { mo da Universidade } \\
\text { de Caxias do Sul } \\
\text { - Caxias do Sul (RS) }\end{array}$ & $\begin{array}{l}\text { Margarita } \\
\text { Barretto e } \\
\text { Mirian } \\
\text { Rejowski }\end{array}$ & $\begin{array}{l}\text { Difusão de pesquisas e } \\
\text { estudos científicos junto } \\
\text { à comunidade acadêmi- } \\
\text { ca, a fim de estabelecer } \\
\text { um fórum de discussão } \\
\text { e comunicação sobre } \\
\text { o desenvolvimento do } \\
\text { turismo no mercosul. } \\
\text { Artigos, comunicações, } \\
\text { sínteses de eventos, rese- } \\
\text { nhas de livros, resumos } \\
\text { de teses e calendário de } \\
\text { eventos. }\end{array}$ \\
\hline
\end{tabular}




\begin{tabular}{|c|c|c|c|c|}
\hline $\begin{array}{l}\text { Título do } \\
\text { periódico }\end{array}$ & $\begin{array}{l}\text { Categoria tipo } \\
\text { periodicidade }\end{array}$ & $\begin{array}{l}\text { Entidade e local } \\
\text { de publicação }\end{array}$ & $\begin{array}{l}\text { Editor ou } \\
\text { responsável }\end{array}$ & $\begin{array}{l}\text { Proposta, conteúdo, } \\
\text { circulação e avaliação }\end{array}$ \\
\hline $\begin{array}{l}\text { Revista } \\
\text { UNIBERO de } \\
\text { Turismo e } \\
\text { Hotelaria } \\
2004 \text { a } 2006\end{array}$ & $\begin{array}{l}\text { Revista científica } \\
\text { eletrônica } \\
\text { semestral }\end{array}$ & $\begin{array}{l}\text { Centro Universitário } \\
\text { Ibero-americano } \\
\text { - São Paulo (sp) }\end{array}$ & $\begin{array}{l}\text { Célia Maria } \\
\text { de Toledo } \\
\text { Serrano }\end{array}$ & $\begin{array}{l}\text { Circulação da produção } \\
\text { acadêmica, visando à } \\
\text { promoção e à divulgação } \\
\text { de estudos e debates } \\
\text { que venham a contribuir } \\
\text { para a construção de um } \\
\text { campo conceitual e de } \\
\text { referências empíricas em } \\
\text { turismo. Artigos e resulta- } \\
\text { dos de pesquisas. }\end{array}$ \\
\hline $\begin{array}{l}\text { Revista Patri- } \\
\text { mônio: Lazer } \\
\text { \& Turismo } \\
2003\end{array}$ & $\begin{array}{l}\text { Revista científica } \\
\text { eletrônica } \\
\text { semestral }\end{array}$ & $\begin{array}{l}\text { Unisantos/COEAE } \\
\text { - Santos (SP) }\end{array}$ & $\begin{array}{l}\text { Mônica Yama- } \\
\text { gawa }\end{array}$ & $\begin{array}{l}\text { Visão multi e interdis- } \\
\text { ciplinar do patrimônio, } \\
\text { lazer e turismo, amplian- } \\
\text { do a discussão sobre o } \\
\text { assunto e a uma maior } \\
\text { consciência da sociedade } \\
\text { a respeito da importân- } \\
\text { cia da preservação para a } \\
\text { memória de uma região. } \\
\text { Artigos. }\end{array}$ \\
\hline $\begin{array}{l}\text { Revista } \\
\text { Eletrônica } \\
\text { Turismo \& } \\
\text { Hospitali- } \\
\text { dade } \\
2003 \text { a ... } \\
\text { (desativada) }\end{array}$ & $\begin{array}{l}\text { Revista científica } \\
\text { eletrônica } \\
\text { semestral }\end{array}$ & $\begin{array}{l}\text { Academia } \\
\text { de Talentos Consul- } \\
\text { toria e Treinamento } \\
\text { - São Paulo (sp) }\end{array}$ & $\begin{array}{l}\text { Haroldo Lei- } \\
\text { tão Camargo }\end{array}$ & - \\
\hline $\begin{array}{l}\text { Boletim de } \\
\text { Estudos em } \\
\text { Hotelaria e } \\
\text { Turismo } \\
2003\end{array}$ & $\begin{array}{l}\text { Revista científica } \\
\text { impressa } \\
\text { semestral }\end{array}$ & $\begin{array}{l}\text { Faculdades Inte- } \\
\text { gradas da Vitória } \\
\text { de Santo Antão } \\
\text { - Recife (PE) }\end{array}$ & Sérgio Leal & $\begin{array}{l}\text { Divulgação de trabalhos } \\
\text { de cunho técnico-cien- } \\
\text { tífico sobre assuntos } \\
\text { relacionados à hotelaria } \\
\text { e ao turismo. }\end{array}$ \\
\hline $\begin{array}{l}\text { Revista Hos- } \\
\text { pitalidade } \\
2004\end{array}$ & $\begin{array}{l}\text { Revista científica } \\
\text { impressa } \\
\text { semestral }\end{array}$ & $\begin{array}{l}\text { Universidade } \\
\text { Anhembi Morumbi } \\
\text { - São Paulo (sp) }\end{array}$ & $\begin{array}{l}\text { Ada de Freitas } \\
\text { Maneti } \\
\text { Dencker }\end{array}$ & $\begin{array}{l}\text { Publicação que aborda } \\
\text { temas e aspectos sobre a } \\
\text { hospitalidade e o turis- } \\
\text { mo, discutindo diversas } \\
\text { relações sociais que } \\
\text { determinam e estimulam } \\
\text { a construção de códigos } \\
\text { culturais. Artigos, rese- } \\
\text { nhas de livros e resumos } \\
\text { de dissertações. }\end{array}$ \\
\hline
\end{tabular}

\begin{tabular}{|c|c|c|c|c|}
\hline $\begin{array}{l}\text { Título do } \\
\text { periódico }\end{array}$ & $\begin{array}{l}\text { Categoria tipo } \\
\text { periodicidade }\end{array}$ & $\begin{array}{c}\text { Entidade e local } \\
\text { de publicação }\end{array}$ & $\begin{array}{l}\text { Editor ou } \\
\text { responsável }\end{array}$ & $\begin{array}{l}\text { Proposta, conteúdo, } \\
\text { circulação e avaliação }\end{array}$ \\
\hline $\begin{array}{l}\text { Revista } \\
\text { Científica } \\
\text { Eletrônica de } \\
\text { Turismo } \\
2004\end{array}$ & $\begin{array}{l}\text { Revista científica } \\
\text { eletrônica } \\
\text { semestral }\end{array}$ & $\begin{array}{l}\text { Faculdade de } \\
\text { Ciências Humanas } \\
\text { de Garça (SP) }\end{array}$ & $\begin{array}{l}\text { Ana Corina } \\
\text { Machado } \\
\text { Spada }\end{array}$ & $\begin{array}{l}\text { Divulgação de estudos e } \\
\text { informações científicas, } \\
\text { colaborando com uma } \\
\text { área ainda muito carente } \\
\text { de pesquisas. Artigos, } \\
\text { resenhas, relatos de caso, } \\
\text { revisões de literatura, } \\
\text { notas técnicas. }\end{array}$ \\
\hline $\begin{array}{l}\text { Revista de } \\
\text { Turismo } \\
\text { Puc/Minas } \\
2005\end{array}$ & $\begin{array}{l}\text { Revista científica } \\
\text { eletrônica } \\
\text { trimestral }\end{array}$ & $\begin{array}{l}\text { Escola Superior } \\
\text { de Turismo da } \\
\text { Puc Minas - Belo } \\
\text { Horizonte (MG) }\end{array}$ & $\begin{array}{l}\text { Herbe Xavier, } \\
\text { Tânia Cristina } \\
\text { Teixeira e } \\
\text { Sylvio Silveira } \\
\text { Santos }\end{array}$ & $\begin{array}{l}\text { Espaço de difusão e inter- } \\
\text { câmbio de saberes sobre } \\
\text { o fazer turístico no Brasil } \\
\text { e no mundo. Artigos } \\
\text { (relatos de pesquisa, } \\
\text { revisões de literatura, } \\
\text { estudos teóricos e relatos } \\
\text { de experiência profissio- } \\
\text { nal), resenhas de livros e } \\
\text { de teses e dissertações. }\end{array}$ \\
\hline $\begin{array}{l}\text { Obsenvatório } \\
\text { de Inovaçāo } \\
\text { do Turismo } \\
2006\end{array}$ & $\begin{array}{l}\text { Revista científica } \\
\text { eletrônica } \\
\text { semestral }\end{array}$ & $\begin{array}{l}\text { Fundação Getúlio } \\
\text { Vargas, em parceria } \\
\text { com a EMBRATur } \\
\text { - Rio de Janeiro (RJ) }\end{array}$ & $\begin{array}{l}\text { Bianor Scelza } \\
\text { Cavalcanti e } \\
\text { outros }\end{array}$ & $\begin{array}{l}\text { Estímulo à produção e } \\
\text { disseminação de conheci- } \\
\text { mentos sobre turismo, } \\
\text { que possam servir ao } \\
\text { debate de temas relacio- } \\
\text { nados à gestão pública e } \\
\text { privada do turismo, em } \\
\text { equilíbrio da teoria com } \\
\text { a prática. Artigos, estudos } \\
\text { de caso e ensaios teóri- } \\
\text { cos; resenhas de livros e } \\
\text { entrevistas. }\end{array}$ \\
\hline $\begin{array}{l}\text { Revista } \\
\text { Turismo: } \\
\text { Dimensōes e } \\
\text { Perspectivas } \\
2001 \text { a ... } \\
\text { (desativada) }\end{array}$ & $\begin{array}{l}\text { Revista científica } \\
\text { impressa } \\
\text { semestral }\end{array}$ & $\begin{array}{l}\text { Faculdades Nobel } \\
\text { - Maringá (PR) }\end{array}$ & $\begin{array}{l}\text { João dos } \\
\text { Santos Filho } \\
\text { Cássia Apare- } \\
\text { cida Guerreiro } \\
\text { Grava }\end{array}$ & $\begin{array}{l}\text { Artigos e sessão de } \\
\text { estudantes. }\end{array}$ \\
\hline
\end{tabular}




(continuação)
\begin{tabular}{|l|l|l|l|l|}
\hline $\begin{array}{l}\text { Título do } \\
\text { periódico }\end{array}$ & $\begin{array}{l}\text { Categoria tipo } \\
\text { periodicidade }\end{array}$ & $\begin{array}{c}\text { Entidade e local } \\
\text { de publicação }\end{array}$ & $\begin{array}{c}\text { Editor ou } \\
\text { responsável }\end{array}$ & $\begin{array}{l}\text { Proposta, conteúdo, } \\
\text { circulação e avaliação }\end{array}$ \\
\hline $\begin{array}{l}\text { RBTur-Revis- } \\
\text { ta Brasileira } \\
\text { de Pesquisa } \\
\text { em Turismo } \\
2007\end{array}$ & $\begin{array}{l}\text { Revista científica } \\
\text { eletrônica } \\
\text { trimestral }\end{array}$ & $\begin{array}{l}\text { ANPTUR-Associação } \\
\text { Nacional de Pesqui- } \\
\text { sa e Pós-Graduação }\end{array}$ & $\begin{array}{l}\text { Margarita } \\
\text { Barretto e } \\
\text { Sênia Regina } \\
\text { Bastos }\end{array}$ & $\begin{array}{l}\text { Disseminação dos } \\
\text { resultados de pesquisas } \\
\text { científicas em turismo, } \\
\text { campo de estudo multi } \\
\text { e interdisciplinar, priori- } \\
\text { zando o diálogo entre as } \\
\text { diferentes perspectivas } \\
\text { de conhecimento. Arti- } \\
\text { gos, resenhas de livros e } \\
\text { síntese de eventos. }\end{array}$ \\
\hline $\begin{array}{l}\text { Revista de } \\
\text { Turismo } \\
\text { Início não } \\
\text { identificado }\end{array}$ & $\begin{array}{l}\text { Revista técni- } \\
\text { co-científica } \\
\text { eletrônica }\end{array}$ & Faculdades Nobel & & \\
\hline
\end{tabular}

Fonte: Exemplares diversos dos periódicos pesquisados.

\section{Considerações finais}

A realização desta pesquisa exploratória, apesar de seu caráter preliminar, possibilitou um novo olhar sobre a comunicação científica em turismo, com base nos periódicos científicos publicados de 1970 a 2007. Pode-se, portanto, compreender a evolução dos periódicos científicos (boletins e revistas) editados no Brasil, cujas propostas editoriais configuram três fases editoriais.

A fase inicial intermitente - periódicos técnico-informativos nas décadas de 1970 e 1980, traz o que se pode considerar como os antecedentes dos periódicos científicos, ou seja, têm-se revistas técnico-informativas de faculdades ao lado de boletins de centros de pesquisa localizados em universidades. É lamentável que tais boletins não tenham evoluído junto com esses centros de pesquisa, acabando por conformar meros laboratórios de cursos de graduação na área. Ambas as IES - a PUC de Campinas e a Universidade Católica de Petrópolis - não voltaram a publicar revistas nas fases que se seguiram. Seria interessante pesquisar por que justamente essas instituições particulares de caráter confessionário originaram tais centros e publicações a eles relacionadas.

A fase da inovação científica - surgimento e consolidação de periódicos científicos na década de 1990 é caracterizada pelo surgimento e pela consolidação dos primeiros periódicos de caráter eminentemente científicos. No entanto, por razões de sustentabilidade financeira e da concorrência com a informação on-line, o pri- meiro e mais tradicional veículo de comunicação científica em turismo - a revista Turismo em Análise - encontra-se com dificuldade de manter sua forma impressa. Assim como ela, outros periódicos desta fase e da terceira fase (ainda impressos) deverão, em breve, assumir a forma eletrônica. Aqueles que contarem com apoio institucional talvez ainda publiquem, conjuntamente com a edição eletrônica, uma pequena tiragem impressa para fins de distribuição institucional gratuita.

A fase da expansão científica - revistas impressas $x$ revistas eletrônicas na década de 2000 mostra claramente a maioria dos periódicos científicos sendo publicados eletronicamente, com acesso aberto e gratuito, situação que se relaciona diretamente à redução dos custos editoriais, à melhoria do sistema de circulação, além de facilidade e rapidez no acesso. Entretanto, a publicação exclusiva em língua portuguesa ainda restringe a efetiva mundialização de seus conteúdos. E ainda há necessidade de aperfeiçoamento de sua visibilidade, sua usuabilidade e sua qualidade, para o cumprimento de seu papel na comunicação científica em turismo.

Nessas três fases, pontuaram-se aspectos da situação atual e algumas tendências futuras da comunicação científica em turismo no Brasil, sugerindo preocupações como as relacionadas a seguir.

- Qual será a sobrevivência das revistas científicas eletrônicas recentemente criadas, ao lado do questionamento de seus padrões de visibilidade, usuabilidade e qualidade?

- Tais publicações estão disseminando estudos e pesquisas originais e inovadoras e, portanto, contribuindo para o avanço do conhecimento científico na área, ou estão oferecendo reproduções da literatura especializada e ensaios roteirizados de aulas?

- Como estimular e apoiar a entrada das revistas científicas em turismo em indexadores e portais, para o seu alcance levar à abrangência internacional?

Conclui-se que a produção e posterior divulgação, em periódicos, das pesquisas científicas realizadas no Brasil guarda relações com a percepção da importância da pesquisa por parte de determinadas instituições de ensino, e pelo prestígio do curso de turismo em outras. Atualmente, ainda que se note a disseminação em meio eletrônico, nota-se também uma redução no volume de artigos publicados. A produção científica brasileira necessita de veiculação em outros idiomas, para que possa ser reconhecida internacionalmente, estimulando intercâmbios e parcerias que possam justificar mais investimentos e maior longevidade das revistas. 


\section{Referências bibliográficas}

ASSOCIAÇĀO BRASILEIRA DE NORMAS TÉCNICAS. 2002. NBR 6023: Informação e documentação: Referências - Elaboração. Rio de Janeiro, 24p.

BANDEIRA, Milena Berthier. 2006. Comunicação científica eletrônica em turismo - periódicos "on line" editados no Brasil. In: REJOWSKI, Mirian \& BASTOS, Sônia Regina. Anais do IV Seminário da Associação Nacional de Pesquisa e Pós-Graduação em Turismo. São Paulo: Aleph, 17p. (CD-Rom).

BERTUZZO, Gleid Maria Pereira. 2004. Produção científica: um estudo cienciométrico do periódico Turismo em Análise. (Não publicada)

CÔRTES, P. L. 2006. Considerações sobre a evolução da ciência e da comunicação científica. In: POBLACIÓN, D. A.; WITTER, G. P. \& SILVA, J. F. M. Comunicação e produção científica: contexto, indicadores e avaliação. São Paulo: Algellara, p. 33-56.

GONÇALVES, Andréa; RAMOS, Lúcia Maria S. V. C. \& CASTRO, Regina C. F. 2006. Revistas científicas: características, funçōes e critérios de qualidade. In: POBLACIÓN, D. A.; WITTER, G. P. \& SILVA, J. F. M. Comunicação e produção científica: contexto, indicadores e avaliação. São Paulo: Algellara, p.163-190.

McKERCHER, Bob, LAW, Rob \& LAM, Terry. 2006. Rating tourism and hospitality journals. Tourism Management, London, Elsevier, n. 26, p. 1235-1252.

MORRISON, Alastair. 2003. Tourism, hospitality and leisure journals. Perdue Tourism and hospitality Research Center, West Lafayette, Disponível em: <http://omni.cc.purdue.edu/\%7Ealltson/journals.htm>.

MULLER, Suzana P. M. 1994. O impacto das tecnologias da informação na geração do artigo científico: tópicos para estudo. Ciência da Informação, v. 23, n. 3, p. 309-317.

PECHLANER, Harald et. al. 2004. A ranking of international tourism and hospitality journals. Journal of Travel Research. USA, Travel and Tourism Research Association, may, p. 328-332.

REJOWSKI, M. \& MINOZZO, C. C. 2004. Periódicos científicos em turismo. Revista de la Asociación Latinoamericana de Carreras Universitarias de Turismo y Hotelería, Mar del Plata, v. 3, n. 1, p. 39-54.

REJOWSKI, M. 1995. Turismo e pesquisa científica: pensamento internacional x realidade brasileira. Campinas: Papirus, 167p.

STREHL, Letícia. 2005. O fator de impacto do ISI e a avaliação da produção científica: aspectos conceituais e metodológicos. Ciência da Informação, Brasília, v. 34, n. 1, jan./abr.

WEITZEL, Simone da Rocha. Fluxo de comunicação científica. In: POBLACIÓN, D. A.; WITTER, G. P. \& SILVA, J. F. M. Comunicação e produção científica: contexto, indicadores e avaliação. São Paulo: Algellara, p. 81-114.

YUKSEL, A. 2003. Writing publishable papers. Tourism Management. London: Elsevier, n. 24, p. 437-446.

Recebido em: 11/12/2006.

Aprovado em: 03/03/2007. 